\title{
«Presumo que impresas andan»: relaciones de sucesos en No son todos ruiseñores, de Lope de Vega*
}

\author{
Sergio Moreno Jiménez \\ Universitat de Girona \\ sergio.moreno@udg.edu
}

Recepción: 15/04/2018, Aceptación: 02/07/2018, Publicación: 11/12/2018

\begin{abstract}
Resumen
En el contexto de la reelaboración de materiales previos por parte de los dramaturgos auriseculares a la hora de configurar sus obras, el presente estudio analiza la refundición de varias relaciones sobre el viaje de María de Hungría desde Madrid a Barcelona en «No son todos ruiseńores» (1635) de Lope de Vega, como ejemplo de una praxis habitual que encontraría, en las relaciones de sucesos, un género de reelaboración muy atractivo, por cuanto su éxito editorial garantizaba una buena recepción por parte del público de los corrales.
\end{abstract}

Palabras clave

relaciones de sucesos; comedia nueva; Lope de Vega; Parte XXII

\begin{abstract}
"Presumo que impresas andan": relaciones de sucesos in Lope de Vega's No son todos ruiseñores

This essay aims to inquire into some of the possible connections between Lope de Vega's narration on Maria of Hungary's visit to Barcelona in 1630, included in his play No son todos ruiseñores, and the relaciones de sucesos (single-event news reports) published in Spain that (literally and also literarily) covered the same event.
\end{abstract}

\section{Keywords}

relaciones de sucesos; urban comedy; Lope de Vega; Part XXII

* El presente trabajo se enmarca en el proyecto con referente FFI2014-53050-C5-5-P, subvencionado por el Ministerio de Economía y Competitividad, a través de una beca FI-DGR. 
Maria Grazia Profeti ha puesto de relieve el interés de Lope por insertar relatos sobre hechos de actualidad en sus comedias, señalando la doble motivación de añadir un género más a los varios que amalgaman su obra dramática, y su capacidad constante para llamar la atención del público con relatos en principio ajenos a la narración principal y que, a su vez, pudieran resultar de interés para los espectadores. ${ }^{1}$ En ocasiones, sin embargo, el Fénix decide inscribir la acción de la comedia en un momento histórico reciente con el fin de revestirla de unas circunstancias concretas, cosa que, por cierto, no impide dedicar uno o más excursos dramáticos a describir tales circunstancias. En este caso, sin embargo, el proceso se da a la inversa: ya no es que un personaje refiera a otro su estancia en Valencia durante las dobles bodas regias de 1599, sino que el hecho histórico está ocurriendo simultáneamente al desarrollo de la acción y, por lo tanto, los personajes no pueden excusar referirse a él en uno o varios momentos de la obra. En los casos en que, además, el autor no se halló presente, es donde encontramos a un Lope menos conocido: el lector asiduo - y ocasional productor - de relaciones de sucesos. ${ }^{2}$ En este trabajo se pretende aislar y analizar los fragmentos de la comedia No son todos ruiseñores a la luz de las relaciones de sucesos contemporáneas dedicadas a narrar los hechos sobre los que el poeta inscribirá la acción de la comedia. ${ }^{3}$ A menudo, como veremos, este tipo de análisis puede brindarnos información teórica de diversa índole: en primer lugar, sobre cómo el autor reelabora este tipo de materiales previos - ya sean escritos, como es el caso de las relaciones de sucesos, o bien orales, epistolares, etc.- de forma simultánea al propio proceso de composición de una pieza dramática; y por otro, nos otorga una idea de la importancia que este género - entre periodístico y literario - alcanzó a tener en la época, hasta el punto de que varios autores los utilizan e incluso muestran un interés generalizado en incorporarlos a sus comedias. Además, el cotejo entre las relaciones y la comedia puede llevarnos, como veremos, a la identificación y enmienda de errores textuales.

El argumento, por lo demás, no tiene mayor relevancia: un enredo amoroso entre el protagonista masculino y el femenino, y sus respectivos criados, en el contexto de las carnestolendas barcelonesas de 1630, que coincidieron ese año con el paso de la comitiva que acompañaba a la futura reina María de Hungría a reunirse con su marido en Viena. Aparte del contexto histórico, tanto la trama como los protagonistas son ficticios, hecho que favorece ya el uso de las relaciones de sucesos, un género precisamente entre la descripción fidedigna y la inclusión de detalles sensacionalistas. En este caso, los hechos reales hallados en la narración corresponden a dos tipos diferenciados. Por un lado, encontramos el parlamento de don Juan, protagonista castellano de No son todos ruiseñores, que refiere lo acon-

1. Profeti (2012).

2. Véase Ettinghausen (2000: 93-106).

3. A falta de ediciones modernas, empleo aquí la Base de Datos Teatro Español del Siglo de Oro (TESO), autorizada por Miguel Ángel Auladell. 
tecido a la comitiva en el periplo desde Madrid a Barcelona y es, por lo tanto, una breve relación inclusa en la comedia. Por otro, puesto que la propia acción transcurre aproximadamente entre febrero y junio de 1630 en Barcelona, a menudo los personajes se refieren a lo que está ocurriendo a su alrededor: las carnestolendas, el alarde de galeras, la despedida de la comitiva regia, etc.

En efecto, el 26 de diciembre de 1629, a la una de la tarde, ${ }^{4}$ salía del Palacio Real María Ana de Austria y Austria-Estiria, acompañada de su hermano, el rey Felipe IV, su cuñada y sus sobrinos. El viaje duró catorce meses, pues cada una de las ciudades por las que debía pasar el séquito real había dispuesto las suntuosas fiestas de rigor a tal evento. Las hubo en Madrid a la salida, en Alcalá, en Guadalajara, Zaragoza y Barcelona, ciudad ésta desde donde la comitiva zarpó en barco hacia el norte de Italia, y de allí a Viena, donde los recién casados habían de reunirse. No más de un año después debía estar ya terminada la comedia No son todos ruiseñores. 5 El Fénix, que no formó parte de la comitiva, da sin embargo numerosos detalles del paso por la Ciudad Condal e incluso por Zaragoza; detalles que, por lo tanto, tuvo que conocer a través de las numerosas relaciones de fiestas conservadas. Asimismo, cada acto de la obra - o jornada, como se les llama aquí- se enmarca en un acontecimiento de los que tuvieron mayor importancia: el primero, en el día de Carnaval, con las máscaras y bailes (se trata del menos detallado, puesto que en él se inscribe el relato del viaje del protagonista desde la salida de Madrid hasta llegar a Barcelona, y por lo tanto, de haber añadido referencias extensas a los acontecimientos que estaban teniendo lugar en Barcelona, hubiera quedado sobrecargado); el segundo, en el alarde de las galeras llevado a cabo en la marina; y el tercero, en el torneo. La acción de la obra, por lo tanto, abarcaría los casi cuatro meses discurridos entre Carnaval y el 12 de junio de 1630, día de la partida de la reina. Es posible que Lope, como ya había hecho en otras obras, ${ }^{6}$ se sirviera de algunas relaciones que detallaran los sucesos acaecidos durante el viaje de la reina.

En cualquier caso, el análisis en paralelo entre los fragmentos extraídos de las relaciones y los versos coincidentes en la obra no pretende dar fe de una irrefutable concomitancia textual, sino más bien tiene como objetivo analizar bajo qué mecanismos pudo Lope haber adaptado los hechos narrados en las

4. Robles, Relación verdadera, acompañamiento, recámara y riquezas que lleva la majestad de la serenisima Reina de Hungria, títulos, grandes, criados, y demás gente que vienen en su servicio, oficios, mercedes que se les ha hecho antes de partir, riquezas y joyas de valor que el Rey nuestro señor le ha dado a ella, como también para el Emperador y Emperatriz, sus cuñados, 1630: «La salida fue miércoles, 26 de deziembre, una hora después del mediodía», $\mathrm{f}$. $1 \mathrm{r}$.

5. El terminus ad quem no es la publicación de la Parte XXII (Madrid, 1635) — preparada, sin embargo, desde mucho antes, pero retrasada debido a la prohibición de Felipe IV para publicar partes de comedias entre 1625 y 1634 - , sino la primera noticia conservada sobre una representación de esta obra el 4 de diciembre de 1633 en Granada. Véase Shergold y Varey (1963: 237).

6. Véase Ramos (2011) y Profeti (2012). 
relaciones a la narración dramática, con qué fines y, por último, en qué medida este tipo de análisis puede ayudar a la comprensión de la obra e incluso a la subsanación de errores textuales.

En un largo fragmento de la "Jornada primera», don Juan, el protagonista castellano de No son todos ruiseñores, relata a su amada Leonarda la llegada a Barcelona desde la salida de Madrid, deteniéndose asimismo en el paso por Zaragoza (vv. 530-726): ${ }^{7}$

El príncipe que traía

a la real desposada las joyas de su marido llegó a la corte de Espańa. Pintarte, Leonarda, el día y por el Prado la entrada, fuera cantar en abril las flores que mira el alba. El gran condestable, en fin, de Castilla le acompaña y toda la corte a él.

Piensa cadenas terciadas, que es en lo que se han resuelto aquellas galas pasadas. Que tampoco en las antiguas se usaron gorras y capas, sino capuz y bonete del modo que los retratan los mármoles de sepulcros, que apenas el tiempo acaba. De manera que los trajes unos vienen y otros pasan, todo consiste en el uso, que califica las galas.

Con esto el gran condestable de Castilla le acompaña, donde el príncipe tenía prevenida la posada. Medinaceli después, Cerda que entonces trocara por sus hebras de oro el sol con tanta grandeza y galas, le lleva a palacio, adonde, con las estrellas de España y la luna de Isabel

7. Nótese que todo el largo fragmento es un romance, porque, evidentemente, «las relaciones piden los romances». Lope de Vega, Arte nuevo de hacer comedias en este tiempo, v. 309. 
el sol Felipe le aguarda.

Llegó, alegrose la corte

y con discreta embajada

dio parabién a la novia

a quien las joyas iguala

con que he dicho las que fueron.

Se refiere primero a la llegada a Madrid, unos meses antes, del embajador alemán, el duque de Guastala — Guastalla, antiguo ducado en el norte de Italia tradicionalmente ligado a los Austria a través de la rama Gonzaga-, el 3 de octubre de 1629. Traía el embajador las joyas enviadas por Fernando de Hungría a su futura esposa, como regalo por las bodas celebradas in absentia el 23 de abril de ese mismo año. Aunque no cabe descartar que Lope conociera estos datos de primera mano, pues por entonces se hallaría en Madrid, ${ }^{8}$ tres son las relaciones de sucesos conservadas que pudieron haberle proporcionado o complementado su información: la primera, de Gabriel Téllez — nada que ver, pese al nombre, con Tirso de Molina_, relata el recibimiento hecho al embajador del rey de Hungría y se cierra con una loa al nacimiento del príncipe Baltasar Carlos Domingo, que fue el 17 de octubre; la segunda, anónima, refiere también el recibimiento del embajador, dando prácticamente los mismos datos, y dedica la segunda parte a narrar el bautismo del príncipe recién nacido, que fue el 4 de noviembre; la última sigue el proceso inverso, pues se centra en el bautismo y anexiona un breve relato sobre la llegada del Duque de Guastala y el recibimiento que se le hizo. ${ }^{9}$ Las tres subrayan como destacada la presencia del Condestable de Castilla, encargado de acompañar al embajador, y de Antonio de la Cerda y Dávila, VI duque de Medinaceli, describiendo con la misma vaguedad que Lope no sólo las libreas y galas de los grandes, sino también las joyas traídas de parte de Fernando III de Hungría para su nueva esposa.

8. Ningún documento directo, pero sí varios datos conocidos, nos obligan a descartar que Lope formara parte del acompańamiento de la reina, empezando por el hecho de que no se le mencione en ni una sola de las relaciones conservadas. Además, el Fénix tenía a la sazón 67 años, edad poco apropiada para traje de camino. Véase Castro y Rennert (1968: 292-299)

9. Respectivamente:

1. Téllez, Breve suma y relación de las grandiosas fiestas que en la corte se hicieron a la entrada del señor Principe de Guástala, embajador de su majestad, el señor rey de Hungría. Con una loa al nacimiento del Principe de España, 1629.

2. Segundas tres relaciones diferentes de las que han salido de la entrada del Duque de Guastala, embajador del Rey de Hungría. Nombrando los nombres de los caballeros, que le salieron a recebir, y joyas que presentó a la Reina de Hungría. Con las estaciones que anduvo la Reina nuestra señora, por el feliz parto que tuvo. Fiestas y máscaras que se han hecho al nacimiento y bautismo del Principe nuestro señor, nombrando por sus nombres las damas y Grandes de España que le acompañaron, con las ceremonias de la Iglesia, s.a.

3. Segunda y más verdadera relación del bautismo del Príncipe de España nuestro señor, Baltasar Carlos Domingo, con todos los nombres de los caballeros, y títulos que iban en el acompañamiento. Con una suma de la entrada del señor Principe de Guastala, embajador de Alemania, 1629. 
Como puede verse, en cualquier caso, las tres relaciones conservadas sobre el recibimiento hecho al embajador alemán aprovechan para referirse como de paso al nacimiento o el bautismo del infante Baltasar Carlos. Lo mismo hace el Fénix, pues el monólogo del protagonista de No son todos ruiseñores, centrado hasta aquí en el recibimiento del duque de Guastala, pasa precisamente a narrar los sucesos sobre el nacimiento y bautizo del infante:

Pero trujo el cielo a Espańa

en este tiempo, la joya

de más valor e importancia,

que le ocupaba el deseo

y le perdió la esperanza.

Halló un diamante en su mina, nació una perla en su nácar,

y fue enigma que de un lirio

o la flor de lis de Francia,

saliese un león al mundo

para vencer los del Asia.

Las fiestas de su bautismo

presumo que impresas andan

y que han cantado las musas

toros y juegos de cañas.

Por lo tanto, Lope narra los acontecimientos a partir de una dispositio simétrica a las de las relaciones, sin aportar datos nuevos o impresiones personales. Ello, sumado a que los autores de las relaciones tendían a copiarse entre sí, puede sugerir que el Fénix estuviera nutriendo su relato con alguno de estos textos, o con otro hoy perdido. En todo caso, pese a que el gusto de la época demandaba una descripción detallada de las galas y torneos, el fragmento dedicado a las joyas traídas por el $\mathrm{Du}$ que de Guastala no se refiere más que a unas "cadenas terciadas», y el del bautismo solo menciona brevemente los «toros y juegos de cañas». Ahora bien, puesto que las relaciones conservadas tampoco son más pródigas en detalles, deberíamos suponer que, en el caso de estar siguiendo alguna de estas relaciones, Lope no habría tenido más información a que atenerse en la elaboración de su propio relato.

Sin embargo, recordemos que, como sucede en la comedia, dos de las relaciones mencionadas arriba [n. 7, núms. 1 y 2] aprovechan, al relatar la llegada del duque de Guastala a la corte, para referir las circunstancias del natalicio y bautismo del príncipe Baltasar Carlos. Si a ello sumamos que la primera de ellas, además, incorporaba una "Loa al nacimiento del Príncipe de Espańa» en la que se mencionaban los juegos de cańas que llevó a cabo la nobleza, ${ }^{10}$ puede conjetu-

10. Téllez, Breve suma..., «Loa del nacimiento», vv. 21-24:

Duques, Marqueses, señores,

repartidos en quadrillas, 
rarse que Lope conoció, si no varias relaciones sobre estos sucesos, al menos sí la Breve suma de Gabriel Téllez. La clave aquí reside en el hecho de que Lope mencione que tales relaciones las "han cantado las musas", por lo que debe referirse a una composición poética, y la única relación que incorpora una es la mencionada Breve suma. En todo caso, Lope puede estar refiriéndose a una composición perdida y, por lo tanto, los únicos argumentos aportados para defender esta teoría se sostienen sobre la dispositio paralela entre ambos textos y la insinuación de la existencia de un romance sobre los toros y juegos de cańas celebrados por el natalicio real. ${ }^{11}$ Así, lo dicho hasta aquí no es suficiente para afirmar que los datos de Lope provengan ni de la Breve suma de Téllez ni de otra cualquiera de las relaciones mencionadas. Baste, por el momento, señalar únicamente esa posibilidad, pero sin olvidar que los hechos narrados ocurrieron en la misma corte y que, por lo tanto, Lope pudo ser testigo directo de todo $-\mathrm{o}$, cuando menos, conocer los detalles de oídas - sin necesidad de recurrir a fuentes secundarias. De hecho, los versos siguientes conforman otro largo excurso dedicado a elogiar la caballería de Felipe IV [vv. 586-634] que, a falta de referencias concretas, posiblemente sea genuino. ${ }^{12}$

Sin embargo, al llegar a la capital aragonesa, se otorgan algunos detalles que Lope no pudo conocer sino por fuente secundaria: ${ }^{13}$

dos a dos, huvo carrera,

galán el que más podía...

11. Las únicas dos relaciones conservadas dedicadas exclusivamente a la narración de estos festejos están en prosa y no aportan detalles suficientes para encontrar una concomitancia clara con el texto de Lope:

1. Santiago, Relación verdadera de las fiestas reales, toros y juego de cañas que se celebraron en la corte, a doce de noviembre, por el nacimiento del Principe nuestro señor, con la declaración de los trajes, galas, y libreas de todas las cuadrillas, Madrid, 1629.

2. Quirós, Relación verdadera de las grandiosas fiestas que se hicieron en Madrid al bautismo del Principe nuestro señor, Madrid, 1629.

12. Aunque Santiago, Relación verdadera de las fiestas reales, toros, y juego de cañas, dedica también gran parte de la segunda mitad de su noticiario a elogiar la equitación del rey. Recordemos que ésta era, además, la relación que con más detalle se refería a los toros y juegos de cañas que también menciona Lope en el v. 586.

13. En efecto, hasta ocho son las relaciones de que tengo noticia sobre el paso del séquito real por la ciudad:

1. Prada y Rivera, Historia de la jornada a Alemania de la Reina de Hungría, después Emperatriz, Infante de España, a quien acompañó hasta Zaragoza el Rey su hermano, 1630.

2. Peirón y Queralt, Verdadera relación de las fiestas que la imperial ciudad de Zaragoza ha hecho a su Rey y señor Filipo III en Aragón, y IIII en Castilla. Dedicada a los muy ilustres señores don Lope de Francia, señor de Bureta y jurado en Cap, don Diego Martel, don Jusepe Cerdán, don Diego Pérezy don Martín Tomás de la Nuza, supremos Atlantes y jurados de dicha ciudad, Zaragoza, 1630.

3. Relación verdadera de la entrada, recebimiento, y grandiosas fiestas que la ilustre ciudad de Zaragoza hizo a sus majestades desde ocho de enero, hasta catorce del dicho mes. Dase cuenta del torneo y saraos que se hicieron, y Grandes que se hallaron en ellas, nombrándolos por sus nombres. Así mismo se declara las costosas libreas que sacaron, y premios que se dieron a las damas de la señora Reina de Hungria, Madrid, 1630. 
Con esto dieron principio

a su dichosa jornada,

donde la ciudad de César

al mayor del mundo aguarda.

Ciudad y diputación

al gran Felipe y su hermana

las manos reales besan

y para servirle alargan

las suyas, lo que permiten

los tiempos; pero las almas,

las voluntades ofrecen

con que le reciben y aman.

Esto fue martes, y un jueves

las cuatro estrellas del Austria,

rey, reina, Carlos, Fernando,

visitaron la sagrada

coluna atlante del cielo,

en cuyo estremo descansa.

Obviamente, «la ciudad de César» se refiere a Zaragoza (por Cesaraugusta, antiguo nombre de la ciudad), al igual que la «coluna atlante del cielo» es el Pilar de la basílica. Sólo tres de las ocho relaciones conservadas dan cuenta del recibimiento y la visita al Pilar por parte de los reyes e infantes. ${ }^{14}$ Ellas corresponden a la segunda, tercera, y cuarta-quinta (pues son la misma, con pocas variantes) mencionadas arriba [n. 11]. Por algún motivo, Lope evita referirse a las representaciones de comedias a que asistieron los reyes e infantes el mismo martes o

4. Torneo de a caballo hecho en Zaragoza por la venida de la serenisima Señora Reina de Hungría, en presencia del Rey nuestro señor, y de los serenisimos Infantes sus hermanos. Relación escrita de orden de la señora Reina por un caballero de la cámara del Rey nuestro señor. Publicado por don Miguel Batista de Lanuza, Zaragoza, 1630.

5. Argensola, Relación del torneo de a caballo con que la imperial Zaragoza solemnizó la venida de la serenisima Reina de Hungría y de Bohemia, Infanta de España, presentes el Rey nuestro señor, y los dos serenisimos Infantes sus hermanos, que a su magostad acompañaron. Escrita a instancia de la misma insigne ciudad, y dedicada a los muy ilustres señores don Lope de Francia y Espés, señor de Bureta, Diego Martel, Jusepe Cerdán, Diego Pérez, y Martín Tomás de Lanuza, jurados y regidores della, Zaragoza, 1630.

6. Felices de Cáceres, Torneo de a caballo en campo abierto que celebró la ciudad de Zaragoza en la venida de la serenisima Reina de Hungría. Presentes del Rey nuestro señor y los serenísimos Infantes sus hermanos. Dedicado a la misma ciudad, Zaragoza, 1630.

7. Relación del torneo verificado en la ciudad de Zaragoza en ocasión de la llegada de la Reina de Hungría y Bohemia en el año de 1658 [sic], Zaragoza, 1630.

8. Entrada, regocijos y fiestas, que la Imperial Ciudad de Zaragoza ha hecho a la majestad del Rey nuestro señor, y Reina de Hungría, y sus hermanos, y los caballeros que se han señalado en ellas, con lo demás que se ha hecho, hasta que su magestad se ha vuelto. Enviada a un caballero desta Ciudad, Barcelona, 1630.

14. Cuatro, en realidad, pero la de Prada y Rivera nunca llegó a imprimirse y, por lo tanto, cabe presumir que su acceso fue limitado y quedaría restringido a un ambiente exclusivamente zaragozano. 
el miércoles, el jueves o viernes, y el sábado, según las fuentes. ${ }^{15}$ Continúa don Juan, el protagonista, con la relación:

El domingo fue la fiesta

para quien armas y galas,

la nobleza de Aragón

quiso igualar a su fama.

Fue grande la bizarría

del de Sástago y Aranda,

Fuentes, Gelves y Jurados,

de que hay relaciones largas.

Cabe hacer aquí un excurso para mostrar cómo el cotejo entre las relaciones conservadas y la comedia puede también brindarnos información de tipo textual, e incluso permite enmendar el texto de la comedia, puesto que, en este caso, no leyeron bien el manuscrito el amanuense o los componedores en el v. 687. En 1630, el condado de Gelves se hallaba en poder de Catalina de Castro y Portugal, cuyo hijo, Pedro Nuño Colón de Portugal y Castro, tenía entonces quince ańos y todavía no era conde. Por mucha que fuera la bizarría de la condesa, no hubiera sido un torneo el lugar más adecuado para hacer gala de ella. Por otro lado, en las relaciones de estas justas no consta que los condes de Gelves asistieran; si lo hicieron debió ser, en todo caso, como meros espectadores. ${ }^{16}$ En cambio, sí participó en ellas, y tomando un papel relevante, don Manuel Belvís, Caballero del Hábito de Santiago, hijo y sucesor del marqués de Benavides, quien además se llevó uno de los premios del torneo: al más galán. ${ }^{17}$ Es decir, alguien — que pudo ser el propio Lope- trivializó un apellido común, Belvís, que sólo podía entenderse conociendo las circunstancias de estas fiestas, por un renombrado título de Gelves, por entonces aún en posesión de los descendientes del almirante Colón. Algo parecido ocurre con el Jurados del mismo verso: lejos de tratarse de un apellido más de la lista, se refiere a los jueces del torneo, de cuya importancia en el mismo se hacen eco todas las relaciones de época. ${ }^{18}$

15. «En la noche del martes siguiente se representó en palacio la comedia de Tirso De tu enemigo, el primer consejo por Luisa de Robles, autora por S. M [...] El miércoles hubo fuegos en el río. El jueves comedia en palacio, de Lope de Vega. El viernes luminarias. El sábado se representó por Luisa Robles la comedia El Confuso agradecido, y el domingo tuvo lugar el torneo.» (Peirón y Queralt, Verdadera relación de las fiestas...); «El viernes y sábado hubo en palacio comedias y otros entretenimientos, de que no poco gustó su Majestad» (Relación verdadera de la entrada, recebimiento...).

16. Tampoco es probable que haga referencia a Diego Carrillo de Mendoza y Pimentel, único marqués de Gelves y conde del Priego, a la sazón octogenario.

17. Argensola, Relación del torneo de a caballo..., párrafos 17, 23 y 26; y Felices de Cáceres, Torneo de a cavallo en Campo abierto...

18. Debe editarse, por lo tanto, en minúscula. De referirse a un personaje concreto, éste sería don Lope de Francia, señor de Bureta y jurado en cap del reino, antiguo cargo de la diputación aragonesa cuya elección se realizaba por sorteo. 
Los cuatro únicos nombres conocidos que da Lope al evocar las fiestas zaragozanas - Sástago, Aranda, Fuentes y Belvís - aparecen en todas las relaciones como protagonistas indiscutibles del torneo. Los condes de Sástago y Aranda eran los respectivos generales de cada uno de los dos bandos ficticios; ${ }^{19}$ el conde de Fuentes, don Juan Fernández de Heredia, se llevó el «premio a la mejor lanza» —el más apreciado—; y don Manuel Belvís, el ya mencionado "premio al más galán». ${ }^{20}$ Por lo tanto, no es posible, a partir de estos datos, descartar como fuente del fragmento ninguna de las ocho relaciones zaragozanas conservadas. Sin embargo, Lope concluye su particular relación del paso de la corte por la ciudad del Pilar precisando que el rey y su séquito se despidieron y partieron para Madrid el día siguiente al torneo:

Lunes fue eclipse de sol;

digo, que quedó eclipsada

la luna, porque en la tierra

también la ausencia le causa.

Partiose su majestad

con sus altezas; no hagas

reflexión en su memoria

de quién partía y quedaba.

Dato que sólo traen los anónimos titulados Relación verdadera de la entra$d a$, recebimiento y grandiosas fiestas que la ilustre ciudad de Zaragoza hizo a sus majestades desde ocho de enero, hasta catorce del dicho mes, y la Entrada, regocijos $y$ fiestas [n. 11, núms. 3 y 8], de los que además el primero es el único de los ocho que fue impreso en Madrid. ${ }^{21}$ No puede asegurarse, sin embargo, que Lope no conociera más de una de estas relaciones, especialmente la de Argensola, que trata de manera muy detallada los hitos del torneo y que conoció una amplia fortuna en esos años. Dos motivos obligan a descartar la Entrada, regocijos y fiestas [n. 11, núm. 8]: primero, el que fuera impresa en Barcelona y que, por lo tanto, no pueda garantizarse su acceso en Madrid en la época; y segundo, el que se especifique que el lunes se fueron el rey y los príncipes, dejando en Zaragoza a María de Hungría, añadiendo que ella "quedará aquí muchos días» —el resto de información, sin embargo, coincide escrupulosamente con la Relación verdadera. El hecho indiscutible es que el Fénix siguió de cerca las noticias relativas al viaje de María de Hungría, pues a las relaciones

19. Los dos bandos eran, en este caso, Júpiter, en honor al rey Felipe IV, y Cupido, en honor a María de Hungría.

20. Argensola, Relación del torneo de a caballo ..., párrafo 26.

21. En realidad, esta relación no especifica qué día exactamente salió la comitiva, pero sí es la única que trata de los preparativos y despedidas llevados a cabo el lunes, aunque termina «dizen partirá la señora Reyna de Vngria en toda la semana» (Cf. Alenda y Mira 1903: I, 267). Posiblemente el título, que se refiere a "ocho de Enero, hasta catorce del dicho mes», contribuyó a la imprecisión. En todo caso, es la única, como digo, de donde Lope pudo sacar el dato. 
sobre la salida de Madrid y la estancia en Barcelona, se suman también, como vemos, las del paso por Zaragoza.

Llegados a este punto, podemos esbozar ya las siguientes conclusiones:

1. Del fragmento relativo a Madrid, si ya es que no fuera Lope testigo directo de todo lo narrado, la relación más cercana por contenido y estructura, así como por contener una narración en verso de los festejos por el bautizo del príncipe Baltasar Carlos —a la cual Lope parece referirse en el v. 586 de la "Jornada primera»—, es la Breve suma de Gabriel Téllez.

2. Sobre el paso de la comitiva por Zaragoza, sólo dos relaciones encajan con todos los datos otorgados por la comedia, de las cuales la anónima Relación verdadera tiene la particularidad de haber sido impresa en Madrid.

3. La comedia transmite además un error que puede subsanarse precisamente a partir de las relaciones de las fiestas zaragozanas al paso de María de Hungría por la ciudad.

4. En el caso de que Lope estuviera efectivamente adaptando los datos de la relación, la amplificatio se reduce a tópicos y figuras poéticas de mediana calidad.

5. Asimismo, el texto dramático trae únicamente los datos de mayor relevancia y que, tal vez por ello, aparecen en todas las relaciones conservadas.

6. En este caso, las pocas pistas sobre la relación que pudo servir de base se circunscriben, como vemos, a la ordenación y otras analogías estructurales, además de a ciertos detalles aportados por sólo una o pocas de las relaciones analizadas.

Por fin llega el relato de don Juan a Barcelona, momento a partir del cual empezamos a encontrar detalles específicos que dejan menos margen a la duda sobre cuáles pudieron ser las relaciones manejadas por el Fénix para enmarcar su relato. Hasta seis, en este caso, son las conservadas sobre el paso del séquito regio por Barcelona, ${ }^{22}$ de las cuales cabe prestar especial atención a tres de ellas, pues

22. Y cuya regesta debemos agradecer al profesor Henry Ettinghausen y a su participación en el volumen de García-Espuche, Ettinghausen, Calvo y Martí (2010).

1. Nogués, Rafael, El majestuoso recebimiento y famosas fiestas que en la insigne Ciudad de Barcelona se han hecho a la majestad de la serenisima Reina de Hungría doña María de Austria, que Dios guarde. Copia primera, Barcelona, 1630.

2. Nogués, Rafael, Noches lucidas, pomposas y célebres fiestas que de noche se han hecho en la insigne Barcelona a la majestad de la serenisima Reina de Hungría que Dios guarde. En diferentes versos, Barcelona, 1630.

3. Los regocijos y fiestas que se hacen en la ciudad de Barcelona por la serenisima majestad de la Reina de Hungría, en particular en las visitas que hace a las casas de religión. Copia segunda, Barcelona, 1630.

4. Relación de las visitas que la majestad de la Reina de Hungría va continuando en las casas de religión, con el espléndido convite que hizo a los pobres en dos días, que fueron el de la Virgen, y el Jueves Santo, lavándoles los pies; y regocijos y estafermo que el Embajador de Hungría en compañia de otros caballeros forasteros, y caballeros desta ciudad, le hicieron en la plaça de San Francisco lunes a 8 de abril 1630, y sarao que en la noche hubo en el Salón de la Puente. Tercera copia, Barcelona, 1630.

5. Pastor Silvano [apócrifo], Relación verdadera de la real embarcación de la serenísima señora 
refieren datos sobre las galeras destinadas a transportar a la comitiva. El primer fragmento al respecto se encuentra en la "Jornada segunda" [vv. 602-613]:

Saliendo don Fernando a la marina, adonde la ciudad concurre agora a ver, por la campańa cristalina, tanta galera que, al salir la aurora, alegra con trompetas los oídos, con banderas los ojos enamora, de que los filaretes guarnecidos, como de las mesanas los penoles de estandartes y flámulas vestidos, con que los alemanes y españoles han de llevar a la imperial María y juntar con dos águilas, dos soles...

La noticia principal que enmarca la acción en esta «Jornada segunda» es, no la salida hacia Génova, como podría parecer, sino un alarde en mar abierto que hicieron las galeras días antes de partir, ${ }^{23}$ dato concreto que traen solamente dos de las relaciones conservadas: la del infatigable cronista Rafael Nogués, y la anónima —o mejor, apócrifa — firmada por un "Pastor Silvano» [n. 20, núms. 1 y 5]. El relato sigue un poco más abajo, en la misma "Jornada segunda» [vv. 637-650]:

Oh mar de España, la contienda y guerra, que el viento de tus olas revestido forma por este tiempo, en paz dilata, deja que llegue el águila a su nido. 640

Una ciudad pacífica retrata,

doña Maria de Austria, Reina de Hungria; que fue Miércoles a los doce de junio, a las siete horas de la tarde, deste presente año de mil seiscientos y treinta, en la muy ilustre e insigne y siempre fidelisima y leal ciudad de Barcelona. La cual contó el Pastor Silvano a su tan querida como hermosa Pastora Celia de los valles de Hebrón; con muchas otras cosas que pasaron, Barcelona, 1630.

Si bien el profesor Ettinghausen incluía en su enumeración tres relaciones más que no se refieren al paso de la comitiva por Barcelona, sino, respectivamente, a la salida de Madrid, las fiestas zaragozanas, y el recibimiento en Nilburgo. A la lista, además, debe añadirse una relación en verso sobre la salida y viaje en barco de la reina hasta Génova que no se incluía en el volumen de GarcíaEspuche, Ettinghausen, Calvo y Martí (2010):

6. Villamayor y Zayas, En la jornada de la serenísima señora Reina de Bohemia y Hungría, desde la Ciudad de Barcelona a Génova. Canción real, Barcelona, 1630.

23. Recuérdese que cada acto se enmarca en un hecho importante del paso de María de Hungría por Barcelona. Así, la "Jornada primera» se centra en el Carnaval, máscaras y bailes; la "Jornada segunda», en el alarde marítimo; y la "Jornada tercera», en el torneo de a caballo y la partida final de la reina. Cada uno de estos hechos históricos confiere además a la comedia un marco temporal que Lope sigue con absoluta fidelidad, de modo que el desarrollo de lo acaecido en el argumento ficticio está adecuado al tiempo transcurrido entre un hecho real mencionado y el siguiente. 
formando como escuadras en hileras, por calles de cristal, campos de plata.

Las prevenidas naves y galeras que la fortuna próspera acompaña a las opuestas galas y riberas, humille su marítima campaña, por que de tanta gloria participe el Golfo de León al león de Espańa con la divina hermana de Felipe.

Si no fuera por las dos relaciones que traen esta noticia, los versos citados podrían pasar como una mención más a las galeras de Barcelona, a sumar a las muchas que pueden encontrarse en los textos de la época. No es el caso, sin embargo, por lo que únicamente cabe preguntarse si pudo Lope extraer sus datos de alguna de las dos relaciones mencionadas. La vaga descripción de las galeras continúa, en boca de la amada de don Juan de Peralta, Leonarda, en los primeros versos de la "Jornada tercera» [vv. 40-90]:

Fui con mi hermano a la famosa playa 40 que de la roja púrpura corona de nativos corales la atalaya, registro de la mar de Barcelona, $\mathrm{y}$ aunque otras mil atarazanas haya donde el arte galeras perficiona, rindan ventaja, a la que lleva el día, que salga en ella la imperial María. Pinta un caballo un célebre poeta diciendo que es el mismo pensamiento tal vez que, de los aires estafeta, desprecia en la carrera su elemento; ya dice que paró veloz cometa esparciendo relámpagos al viento, copiando, por que a Rubens se anticipe el retrato de Júpiter Filipe.

Se refiere Lope, con ese "célebre poeta» [v. 48] a Garcilaso, Epistola a Boscán [vv. 18-28], aunque fundido o confundido consigo mismo, pues los mismos versos evocan la Silva rubeniana del propio Lope, que contiene también un elogio a Felipe IV. La metáfora sobre el caballo veloz como el pensamiento era tradicional, y tanto, que incluso es recreada en una de las crónicas sobre estas fiestas barcelonesas [n. 20, núm. 2]. ${ }^{24}$ Relación que, sin embargo, nada dice

24. Nogués, Noches lucidas, pomposas..., «Silva», vv. 15-20:

Óyese el clarín noble, a cuyo acento

el ligero caballo cobra aliento, 
sobre las galeras imperiales más allá de la obligada referencia barcelonesa, ni del alarde de éstas ocho días antes de la partida. Pese a lo cual, ¿pudo una lectura paralela de esa relación evocar en el Fénix la imagen garcilasiana y, a su estela, la recreación propia?

¿Pues cuánto con mejor pincel, Marcela, este caballo de la mar pintara si su cristal, sirviéndole de tela, en la ribera contrapuesta para?

Los rojos remos de una y otra espuela parecen alas de la fénix rara que volarán, aunque mojadas plumas, rompiendo el agua y levantando espumas. Ha puesto la ciudad tanto cuidado, Marcela, en fabricar esta galera, como si en jaspe o mármol coronado de mil colunas un palacio hiciera. De ébano, de oro y de marfil labrado, el más rico escritorio no pudiera igualar a la popa, que es mentira cuanto en cuadras de príncipes se mira. Estrado pueden ser los filaretes de la más alta y principal señora, los árboles, mesanas y trinquetes más le doran al sol, que el sol les dora: $\quad 75$ flámulas, estandartes, gallardetes, que al sol de Hungría llevarán su aurora con tales ondas el damasco mueven que las del agua con las puntas beben. En esta caja han de llevar al uno de los cuatro diamantes españoles, perla que no la tuvo mar ninguno de cuantos vieron popas y faroles. El frío en Alemania es importuno, por eso el uno de sus cuatro soles (Filipe, dos infantas, y María) quedándose con tres, España envía. Después que vi, Marcela, el Argos nuevo, que ha de llevar el rubio vellocino, mejor Jasón a más dorado Febo...

pues le infunde animoso

espíritu gallardo

que, sin hallar reposo,

al veloz pensamiento juzga tardo. 
Resumamos aquí las noticias con visos de realidad que transmiten estos versos, desgajadas siempre de la infinidad de tópicos y vaguedades entre los que se encuentran. En primer lugar, tenemos el alarde de las galeras, hecho histórico del que sólo hay noticia por las relaciones de Nogués, El majestuoso recibimiento..., y del Pastor Silvano, Relación verdadera de la real embarcación... [n. 20, núms. 1 y 5], y de las cuales la segunda, en verso, dedica casi toda la primera mitad de la relación a tal suceso, mientras que en la primera hallamos sólo un breve párrafo al respecto. ${ }^{25}$ Asimismo, la narración de Lope y la del Pastor Silvano comparten algunos sintagmas similares, aunque propios de cualquier descripción náutica. Por último, el predominio del rojo decorativo de las embarcaciones es dato que Lope pudo solamente encontrar en esa relación. Veamos las similitudes mencionadas en paralelo:

\begin{tabular}{|c|c|}
\hline Relación verdadera de la real embarcación & No son todos ruiseñores \\
\hline $\begin{array}{l}\text { f. } 2 \mathrm{v} \text { : «Sabrás que ocho días antes / quiso su } \\
\text { majestad sacra / probar de entrar en el mar / para } \\
\text { ver si le dańara». } \\
\text { f. 3r: «La gente que por el mar / y también por la } \\
\text { montaña / de Monjuhique había / no ay guarismo } \\
\text { por contarla // Vieras, Celia, las galeras / con ban- } \\
\text { derolas y flámulas / la Real con gallardetes / que era } \\
\text { una cosa estremada». }\end{array}$ & $\begin{array}{l}\text { Jornada segunda, vv. 602-610: «Saliendo don } \\
\text { Fernando a la marina, / adonde la ciudad concurre } \\
\text { agora / a ver, por la campaña cristalina, / tanta gal- } \\
\text { era que, al salir la aurora / alegra con trompetas los } \\
\text { oídos / con banderas los ojos enamora, / de que } \\
\text { los filaretes guarnecidos, / como de las mesanas los } \\
\text { penoles / de estandartes y flámulas vestidos». }\end{array}$ \\
\hline $\begin{array}{l}\text { f. 2v: «Oh monstruo terrible, y fiero / aunque } \\
\text { tal viento te daba, / que hasta el mejor marinero / la } \\
\text { comida le trocaras // Quiso Dios que ella estuviese } \\
\text { / firme, sin verse que en nada / el mar la dañase, } \\
\text { aunque otras / salieron muy bien purgadas.» }\end{array}$ & $\begin{array}{l}\text { Jornada segunda, vv. 637-640: «Oh mar de Es- } \\
\text { paña, la contienda y guerra, / que el viento de tus } \\
\text { olas revestido / forma por este tiempo, en paz dila- } \\
\text { ta, / deja que llegue el águila a su nido.» }\end{array}$ \\
\hline $\begin{array}{l}\text { f. 4r: «Fuese luego al pasadizo / do las galeras } \\
\text { aguardan / con flámulas y estandartes, / que era } \\
\text { una vista gallarda, // La Capitana de Nápoles / para } \\
\text { cogerla ya estaba / amarrada con la puente / con } \\
\text { una muy linda traza. // Toda la puente ya dicha / de } \\
\text { bayeta colorada, / y tres grandes escaleras / estaban } \\
\text { encub[il.]» }\end{array}$ & $\begin{array}{l}\text { Jornada tercera, vv. 40-47: «Fui con mi hermano } \\
\text { a la famosa playa / que de la roja púrpura corona / } \\
\text { de nativos corales la atalaya, / registro de la mar de } \\
\text { Barcelona, / y aunque otras mil atarazanas haya / } \\
\text { donde el arte galeras perficiona, / rindan ventaja, a la } \\
\text { que lleva el día, / que salga en ella la imperial María.»" } \\
\text { Jornada tercera, vv. 60-79: Los rojos remos de una } \\
\text { y otra espuela / parecen alas de la fénix rara / que vo- } \\
\text { larán, aunque mojadas plumas, / rompiendo el agua } \\
\text { y levantando espumas. / Ha puesto la ciudad tanto } \\
\text { cuidado, / Marcela, en fabricar esta galera, / como si } \\
\text { en jaspe o mármol coronado / de mil colunas un pala- } \\
\text { cio hiciera. / De ébano, de oro y de marfil labrado, / } \\
\text { el más rico escritorio no pudiera / igualar a la popa, } \\
\text { que es mentira / cuanto en cuadras de príncipes se } \\
\text { mira. / Estrado pueden ser los filaretes / de la más alta } \\
\text { y principal seńora, / los árboles, mesanas y trinquetes } \\
\text { / más le doran al sol, que el sol les dora: / flámulas, } \\
\text { estandartes, gallardetes, / que al sol de Hungría lle- } \\
\text { varán su aurora / con tales ondas el damasco mueven } \\
\text { / que las del agua con las puntas beben.» }\end{array}$ \\
\hline
\end{tabular}

25. Nogués, El majestuoso recebimiento..., f. 2r: «Estaba el cielo despejado, y el mar tranquilo, que 
No es fácil, como apuntábamos arriba, discernir entre estos pasajes el mero tópico de la posible fuente. En ambos casos, las descripciones de las galeras no superan un vago elogio poético. No obstante lo cual, sí puede apuntarse que, dado que Lope hubo de utilizar para conocer estos datos alguna relación de sucesos que los transmitiera, ninguna de las conservadas se muestra más digna candidata a este propósito que la apócrifa Relación verdadera de la real embarcación. Varios detalles, como la insistencia en el color rojo en ambos textos o las referencias paralelas a banderolas, fámulas y gallardetes, además de la invocación al mar que hallamos en ambas obras, dan muestras, si no de un evidente paralelismo textual, sí, creo, del empleo y modo de una posible fuente. ${ }^{26}$ Asimismo, la propia escasez de más detalles sobre las embarcaciones es ya un paralelismo en sí.

En la narración de Leonarda, a las últimas menciones de las galeras sigue el relato del torneo que se hizo esa misma noche frente al palacio de los duques de Cardona y la Basílica de la Mercè, en la plaza de San Francisco (hoy, Palacio de la Capitanía General).

Después que vi, Marcela, el Argos nuevo

que ha de llevar el rubio vellocino, mejor Jasón a más dorado Febo,

la negra sombra de la noche vino

en palacio, no sé cómo me atrevo

a decirte, que vi su sol divino,

donde el amor con general deseo

le previno las galas de un torneo

El mismo orden narrativo sigue el doctor Nogués en El majestuoso recibimiento y famosas fiestas, con la diferencia de que el barcelonés menciona un sarao en palacio la noche del alarde de galeras [n. 23], dato que Lope omite y sustituye por el torneo de a caballo, que en realidad tuvo lugar la noche siguiente. Continúa el relato de Leonarda:

Pero esto corta maravilla encierra

para las muchas que sus ojos vieron,

todo festejó a su majestad. Salieron ocho galeras del muelle, y llenas de banderolas y gallardetes se pusieron en hilera delante el pasadizo o puente que años atrás se hizo para la majestad del Rey nuestro señor, de donde las miraba su majestad, hicieron muchas salvas de mosquetería, jugando la artillería a ratos; y esto por espacio de hora y media, a cuyos regocijados tiros respondían las cuatro compañías de arcabuceros, que puestos en la muralla se vio la más agradable ostentación por mar y tierra que vieron los humanos».

26. También da algunos detalles de las galeras, sin mencionar el alarde y con la fecha de la partida equivocada (12 de mayo por 12 de junio), la relación de Villamayor y Zayas, En la jornada de la serenísima señora Reina de Bohemia y Hungría [n. 20, núm. 6]. Los dos errores mencionados obligan, sin embargo, a descartarla a priori como fuente de los fragmentos lopescos, que los habrían transmitido en el caso de que Lope siguiera esta relación. 
pues más de cuatro mil hombres de guerra, entrando [a] la ciudad la recibieron.

Aquí mostró la belicosa tierra 100

de qué valor sus armas procedieron, entoldando los aires tafetanes de tantos generosos capitanes. Puede armar Barcelona, que es trofeo digno de su grandeza, en un instante diez mil soldados, pero ya el torneo, me pide señas de mi dulce amante...

Cabe decir aquí que las dos relaciones del doctor Rafael Nogués [n. 20, núms. 1 y 2] -y, en especial, la llamada "Copia primera»— conocieron una amplia difusión en la época, como muestran las relaciones conservadas a su zaga [n. 20, núms. 3 y 4] y su mención en otras, como la de Villamayor y Zayas. A estas dos relaciones hay que acudir para encontrar los nombres de los «generosos capitanes» que hicieron alarde antes de las justas. Las menciones a los "cuatro mil hombres de guerra" y a los «diez mil soldados», que no aparecen en las relaciones de Nogués, pueden deberse a meras exigencias métricas del endecasílabo.
...en cuatro carros como el mundo veo
dividido el teatro militante,
que le formaron con bastante espacio,
juntándose a la puerta de palacio,
cuatro cuadrillas que, de veinte en veinte,
con las armas la noche hicieron día,
el carro celestial resplandeciente
con los mantenedores parecía.

Nuevamente, parece haber un error de amanuense o componedor en el v. 113: «armas» por achas (sin h según la grafía típica de la época), aunque no está claro que no se refiera realmente al brillo de los escudos y armaduras. Con todo, el tópico de "hacer la noche día» o "volver la noche en día» aparece prácticamente cada vez que se describen unas luminarias en estas relaciones, y es preferencia abundantísima en el doctor Nogués. ${ }^{27}$

Y del doctor Nogués son las dos relaciones que parece seguir Lope en este fragmento sobre el torneo. La primera, El majestuoso recibimiento... [n. 20, núm. 1], escrita en prosa y con mucho detalle, es la más extensa relación conservada del paso de María de Hungría por Barcelona; la segunda, titulada Noches

27. Verbigracia, en El majestuoso recibimiento, y en el mismo fragmento, f. 2v: «Estaban en estas blandoneras que rodeaban la gran plaça las achas tan juntas entre sí, que unas derretían a otras: ellas volvieron aquella noche día». 
lucidas, pomposas... [n. 20, núm. 2], refiere los hitos principales ya descritos en la anterior, pero lo hace a través de una serie de composiciones en verso, empleando diferentes metros — romances, silvas, espinelas y octavas-. Por lo tanto, a menudo el léxico y metáforas que acompañan a una noticia se repiten en la recreación en verso, lo que hace más difícil si cabe asegurar con total certeza de cuál de las dos extrae Lope los datos de este fragmento de la comedia. ${ }^{28}$ No obstante, los vv. 108-109 de la "Jornada tercera» en que nos hallamos, pueden darnos alguna pista al respecto: «en cuatro carros como el mundo veo / dividido el teatro militante». Se refiere Lope a los carros que se empleaban —entre otras cosas, como vemos- para las representaciones de autos sacramentales durante las fiestas del Corpus Christi. En efecto, según transmite Rafael Nogués en sus Noches lucidas, «Octavas», vv. 1-8:

Los pífaros y cajas sonorosos

alientos nuevos al valor informan,

y a su son, los torneantes belicosos

airosos lazos con mil vueltas forman,

y al son mismo los carros luminosos

de cuatro en uno solo se transforman,

las barandas haciendo (hermosa valla)

término incontrastable a la batalla

O bien, en las mismas Noches lucidas, «Romance», vv. 5-8 y 45-48:

Entran cuatro grandes carros

al compás del ronco son

de los pífaros y cajas,

que al aire rompen veloz

...

Sobre estos triunfantes carros,

armado de su valor

y de relucientes armas

viene un hermoso escuadrón

Con algo más de detalle, la referencia a esta máquina se halla también en El majestuoso recibimiento. ${ }^{29}$ Se trata, sin lugar a dudas, de la referencia más

28. La doble redacción en prosa y verso es, en realidad, un recurso típico de las relaciones de sucesos. Cf. Profeti (2001: 227): «Esempio dunque di meticciamento prosa-verso e di reduplicazione della informazione/descrizione, e questa volta nel corpo di una unica relación" (se refiere a la relación sobre el desposorio de Felipe IV, escrita en 1648 por Juan Francisco de Ávila).

29. Nogués, El majestuoso recebimiento..., ff. 3r-v: «Luego, al son de cajas y pífaros entraron cuatro carros, fabricados con grande maestría, tenía cada uno doce varas en largo y ocho por lo ancho, con balaustres al derredor, argentados con sus mascarones; en las esquinas movíanse con unas secretas ruedas que tiraban muchos hombres, que todo se encubría con mucha gra- 
explícita a la relación de Nogués (el singular está justificado porque ambas relaciones no sólo son del mismo autor, sino que están transmitiendo, como vemos, la misma noticia).

Los cuatro versos siguientes parecen encontrar su referente, asimismo, en $E l$ majestuoso recibimiento:

\begin{tabular}{|c|c|}
\hline El majestuoso recibimiento, f. $3 \mathrm{v}$ : & No son todos ruiseñores, vv. 116-119: \\
\hline $\begin{array}{l}\text { "Venían sobre cada una cinco caballeros armados } \\
\text { todos con lanzas y con }[i l .] \text { riquísimos y lucidos, } \\
\text { grandes y vistosas cimeras, con una infinidad de } \\
\text { plumas curiosas y brilladores volantes, conformes } \\
\text { en colores los de cada carro y todos con lanzas de } \\
\text { plata bruñidas.» }\end{array}$ & $\begin{array}{l}\text { Tanta color y pluma diferente } \\
\text { de las celadas fúlgidas salía, } \\
\text { como se ven distintas las colores, } \\
\text { en macetas de plata, varias flores }\end{array}$ \\
\hline
\end{tabular}

En efecto, los paralelismos entre la descripción del torneo que hace Lope y la que presenta Rafael Nogués resultan evidentes. Ello no contradice en absoluto la recreación que hace el primero, especialmente por lo que se refiere al espacio; recordemos que, para la época, ser capaz de decir lo mismo en menos versos era considerado signo de buen poeta.

Ahora bien, ¿̇e dónde sale el «de veinte en veinte» del v. 112? Hay varias posibilidades, desde luego: puede tratarse simplemente de una invención dramática de Lope; puede también haber ocurrido que los cuatro carros mencionados, que en las relaciones aparecían con «cinco caballeros» montados en cada uno, haya dado un número de veinte que Lope decide exagerar. ${ }^{30}$ Sin embargo, parece haber una contaminación con el otro torneo descrito en la anónima $R e-$ lación verdadera de la entrara, recibimiento y grandiosas fiestas que la ilustre ciudad de Zaragoza hizo a sus majestades desde ocho de enero hasta catorce del dicho mes: "A las cuatro de la tarde entraron en la plaza dos suntuosos carros con músicas, representaciones y tramoyas; y sucesivamente fueron entrando los caballeros que

cia, con unos lienços que pendían de las cornisas, en que avía pintada mucha diversidad de caças y peleas marítimas y terrestres, grandes arboladas y hermosas fuentes, todo de valiente pincel. Venían sobre cada una cinco caballeros armados todos con lanças y con [il.] riquísimos y lucidos, grandes y vistosas cimeras, con una infinidad de plumas curiosas y brilladores volantes, conformes en colores los de cada carro y todos con lanças de plata bruñidas hicieron con mucha destreza el debido acatamiento a su majestad, con airosos pasos y gallardos movimientos; començando los Maeses de Campo, que puestos delante los armados, que fueron cuatro, riquísimamente vestidos». Y f. 4r: «Luego, al son de las cajas y pífaros, con mucho espacio se fueron juntando los carros del torneo delante el balcón de su majestad, y haciendo de todos uno, sirviendo de valla las barandas y balaústres de unos y otros, hízose el torneo lo mejor que se pueda desear».

30. En realidad, el alarde se hizo «parejos de dos en dos» (Noches lucidas, «Romance», v. 144), acompañando a los caballeros más importantes «cuarenta lacayos» (e.g., El majestuoso recibimiento... f. $3 \mathrm{v}$ ), lo que podría corresponder a veinte lacayos por caballero, de donde Lope pudo haber sacado su «de veinte en veinte». 
tomaron parte en el torneo, en número de 20». Recordemos que esta relación era, por la concordancia de datos transmitidos con la comedia, la candidata más idónea como fuente del fragmento que describe el periplo zaragozano del séquito real. Pero cabe apuntar que es solamente este dato el trasvasado entre ambas relaciones, pues Lope está siguiendo la de Nogués, como demuestra, por ejemplo, el que sí conozca que en Barcelona fueron cuatro los carros empleados en la parafernalia, y no dos.

Los versos siguientes de la comedia [120-135] refieren por boca de Leonarda los hitos de don Juan en el torneo, primero incógnito de los espectadores, después con su victoria y el rumor ya extendiéndose "de que era caballero castellano» [v. 129] y, por último, de su huida del vulgo con la celada todavía puesta. La mezcla de trama argumental con realidad histórica alcanza aquí su punto álgido. En los demás momentos, como vemos, los hechos históricos son referidos por un personaje, o de una manera general están ocurriendo con simultaneidad a la acción narrada; en este caso, sin embargo, el personaje principal y su escudero participan directamente del hecho histórico con un papel protagonista:

En medio pues, Marcela, de la fiesta, al gran teatro un caballero sube, que aventurero, espada y lanza apresta, en quien la vista, con razón, detuve.

No conociera, la celada puesta, mi amado sol, pues le sirvió de nube, a no ser por Lisardo, su padrino que a darme el precio a la carroza vino. Pasó la voz en el vulgar estruendo de que era caballero castellano, cuando don Juan, con su padrino huyendo, 130 de los curiosos fue seguido en vano.

Acabada la relación de Leonarda, Marcela no puede por menos que exclamar:

Estraña y nunca vista gallardía, atreverse, Leonarda, un caballero castellano, a salir adonde había tanto señor bizarro aventurero.

No tan extrańa, en realidad, y menos nunca vista. Si bien es cierto que no hay noticia de las hazañas particulares de ningún caballero castellano en estas justas - de pantomima, vale puntualizar, pues ni siquiera podemos saber por las relaciones que llegara a haber entrega de premios—, sí aparecen en El majestuoso recibimiento, y repetidas en las Noches lucidas, un par de noticias que pudieron llegar incluso a inspirar el relato lopesco sobre un caballero castellano en el torneo celebrado a merced de la Reina de Hungría: 
Noches lucidas, «Silva I», vv. 33-56:

Los dos famosos cabos de cuadrilla, a cuyo gran valor en vasallaje (que nunca esplendor tanto sufrió ultraje) el diputado militar, airoso, Francisco de Sentís, con el famoso Conde de Monte-Agut, conde que abona la célebre progenie de Cardona, entran a lo español, traje bisarro [describe los colores y las galas] con cuarenta lacayos muy lucidos, en trajes y colores parecidos a sus gallardos dueños, y loçanos, con sendas hachas blancas en las manos, discurren con alegre bizarría vuelta la noche oscura en claro día.

Pese a la parquedad de detalles que ofrece Nogués en sus relaciones para todo lo que no sean las galas, lucimientos y máquina decorativa, sí concede al Diputado Militar vestido a la española, y sólo a él, unos versos para describir su lance:

Noches lucidas, «Silva II», vv. 156-161:

Y luego, al son de bélicas trompetas, el Diputado Militar empieça, y haciendo mil astillas de la lança, rompe otra en el otro que le alcança. Síguenle los demás, bravos y diestros, que de tales acciones son maestros.

También el Oidor Militar Francisco Cánovas y el Vizconde de Jóc aparecieron vestidos de españoles:

Noches lucidas, «Silva II», vv. 116-125:

Para alabar la gracia, gala y lustre del Militar Oidor, del generoso Francisco que es de Cánovas famoso, y del Visconde ilustre que el título de Joch tiene y honora, mi ruda lengua tu favor implora: Vestidos a lo antiguo de españoles, de verde terciopelo a cuya primavera tornasoles de diversos cambiantes hacen Cielo... 
Etcétera. ${ }^{31}$ No se puede asegurar que Lope tomara la idea para la trama de No son todos ruiseñores de estas vagas noticias. Pero tampoco es menos cierto que las relaciones del doctor Rafael Nogués - en realidad, una de ellas, pues como hemos visto, ambas describen, en prosa y verso, las mismas cosas- pasaron por las manos del Fénix, transmitiéndole los detalles más importantes referentes al paso del séquito de María Hungría por Barcelona.

\section{Conclusión}

Creo que todo lo señalado permite dilucidar los materiales empleados por Lope para la construcción de la comedia No son todos ruiseñores, materiales que cabe circunscribir, como mínimo, a la anónima Relación verdadera de la entrada, recebimiento, y grandiosas fiestas que la ilustre ciudad de Zaragoza hizo a sus majestades desde ocho de enero, hasta catorce del dicho mes, para el fragmento zaragozano, y a las dos relaciones de Rafael Nogués, El majestuoso recibimiento... y las Noches lucidas, pomposas... [n. 20, núms. 1 y 2] para el núcleo narrativo ubicado en Barcelona. Dicho esto, debe recordarse que también observábamos paralelismos con la Breve suma de Gabriel Téllez, para la salida de Madrid y el bautizo del príncipe; y con la Relación del torneo de a caballo con que la imperial Zaragoza solemnizó la venida de la serenisima Reina de Hungría y de Bohemia, de Bartolomé Leonardo de Argensola, y, quizá, con la apócrifa Relación verdadera de la real embarcación de la serenísima señora doña María de Austria, Reina de Hungría, firmada por el «Pastor Silvano». No obstante, me parece necesario cerrar estas páginas con unas cuantas conclusiones generales sobre el modus disponendi de Lope.

Vaya por delante que el situar la comedia de manera simultánea a un hecho histórico otorga a la acción narrativa un marco temporal delimitado: en este caso, los cuatro meses que pasó la reina de Hungría en Barcelona, transcurridos entre Carnaval y el 12 de junio de 1630. Sin necesidad de menciones temporales específicas, las breves referencias de los propios personajes a lo que estaba ocurriendo a su alrededor servían de indicio al público para que se situara en la línea temporal trazada: entre Carnaval y el Miércoles de Ceniza en el primer

31. Los fragmentos correspondientes a El majestuoso recibimiento son, respectivamente, ff. $2 \mathrm{v}-3 \mathrm{r}$ : "Y luego, en primero lugar, el señor Francisco Sentís, Diputado Militar, y el señor Conde de Monte Agut, vestidos a la Española, costosísimamente de lama leonada con ricas fajas de oro de Milán, capas agavanadas de la misma guarnición, guarniciones de caballos de lo mismo, con vistosos y grandes penachos leonados, metieron cuarenta lacayos de la misma librea, plumas y galas, si no tan costosas, tan lucidas, con sendas hachas en las manos (y esto se supone en todos los demás); corrieron su carrera parejos con mucha bizarría y destresa haciendo el debido acatamiento a su majestad con las lanças, y esto hicieron los demás por su orden con notable concierto y gallardía». Ibidem, f. 4r: «El Oidor Militar, que es el señor Francisco Cánovas, y el Visconde de Joch, salieron de españoles, a lo antiguo, con calças de obra, capa y gorra, con tanta bizarría y gala, que no hubo más que desear, con cuarenta lacayos de la misma traça. Hase de advertir que todos estos caballeros traían puestas mascarillas muy al propio del traje y nación que representaban». 
acto, dos meses después en el segundo hasta el alarde de galeras del 4 de junio, y desde el último torneo en honor del séquito hasta la partida de la reina en el tercero. Identificar estas referencias no podía dejar de resultar atractivo para el espectador, que conocería, cuando menos a grandes rasgos, las estaciones del periplo regio, sobre todo si, de paso, se le informaba de algunos pormenores que desconocía. Y no en menor medida debió de agradecer tales guińos el público barcelonés, asiduo a las comedias tanto como el de Madrid, Valencia o Sevilla, aunque injustamente falto de argumentos ambientados en su ciudad.

Es un hecho conocido que Lope aprovechó, para la construcción de su dramaturgia, todos los materiales a su alcance, y especialmente los que más podían llamar la atención del público. ${ }^{32}$ Como las revistas de papel cuché hoy en día, las relaciones de sucesos - el equivalente barroco- conocieron una enorme fortuna en la época, y especialmente entre 1580 y $1650 .{ }^{33}$ Huelga decir que el Fénix, gran conocedor y no menos servidor de los gustos del vulgo, no podía dejar de aprovechar ese filón que, por el camino, abría nuevas vetas al proceso de composición de sus comedias. ${ }^{34}$ Pero además, nos encontramos en un período de la producción lopesca en que se aprecia una búsqueda por parte del Fénix de triunfar también fuera de las tablas, casi con la misma fuerza con que en torno a 1600 le veíamos inmerso en géneros como la épica, la novela bizantina, o la lírica a lo divino. Hacia 1630, momento álgido del género llamado relación de sucesos, es fácil comprender que Lope volviera a sus tentativas de juventud, si bien la experiencia y los años mantienen esas tentativas dentro de los cauces del género que lo había consagrado como uno de los grandes ingenios castellanos: la comedia. ${ }^{35}$

32. Sólo a medias puedo coincidir con la afirmación de Profeti (2001: 231): «In questi poeti palatini [i.e., Cubillo de Aragón] si può anche verificare l'infuenza delle relaciones de sucesos in testi letterari, processo inverso a quello effettuato da Lope, in cui é il poema a fagocitare la relación» [p. 231]; no creo que la recreación poética de un suceso inmersa en un texto literario anule per se la influencia de una o varias relaciones. Valga como prueba de ello solamente el caso que aquí nos ocupa.

33. Véanse las interesantes cifras sobre publicación de relaciones en pliegos poéticos del siglo XVII en Rubio Árquez (1996).

34. Véase Ramos (2011), que ofrece un esbozo de tipología de estos procesos de adaptaciónrecreación entre comedias y relaciones de sucesos a través de seis ejemplos lopescos, tres de Calderón, y uno de Moreto.

35. Para un enfoque cercano sobre la búsqueda de la consagración en otros géneros por parte de Lope, véase Profeti (1998). 


\section{Bibliografía}

Alenda y Mira, Relaciones de solemnidades y fiestas públicas de España, Madrid, Sucesores de Rivadeneyra, 1903.

Argensola, Bartolomé Leonardo de, Relación del torneo de a caballo con que la imperial Zaragoza solemnizó la venida de la serenísima Reina de Hungría y de Bohemia, Infanta de España, presentes el Rey nuestro señor y los dos serenisimos infantes sus hermanos, que a su majestad acompañaron. Escrita a instancia de la misma insigne ciudad y dedicada a los muy ilustres señores don Lope de Francia y Espés, señor de Bureta, Diego Martel, Jusepe Cerdán, Diego Pérez y Martín Tomás de Lanuza, jurados y regidores della, Zaragoza, Juan de Lanaja y Quartanet, 1630.

Beltrán, Juan, Relación verdadera de la salida que hizo la señora Reina de Hungría a 26 de deciembre, año de 1629. Con un romance al sentimiento y despedida de la corte, Barcelona, Esteban Liberós, 1630.

Castro, Américo y Hugo A. Rennert, Vida de Lope de Vega, Salamanca, Anaya, 1968.

Entrada, regocijos y fiestas que la imperial ciudad de Zaragoza ha hecho a la majestad del Rey nuestro señor, y Reina de Hungria y sus hermanos; y los caballeros que se han señalado en ellas, con lo demás que se ha hecho, hasta que su majestad se ha vuelto. Enviada a un caballero desta ciudad, Barcelona, Esteban Liberós, 1630.

Ettinghausen, Henry, «¿Lope reportero? Su Relación de las fiestas de San Isidro", Anuario Lope de Vega, VI (2000), 93-106.

Felices de CÁceres, Juan Baptista, Torneo de a caballo en campo abierto que celebró la ciudad de Zaragoza en la venida de la serenisima Reina de Hungría. Presentes del Rey nuestro señor y los serenisimos infantes sus hermanos. Dedicado a la misma ciudad, Zaragoza, Diego Latorre, 1630.

García-Espuche, Albert, Henry Ettinghausen, Lluís Calvo y Josep Martí, La ciutat del Born. Barcelona 1700. Festes i celebracions, Monografies del Museu d'Història, Barcelona, Institut de Cultura de Barcelona-Ajuntament de Barcelona, 2010.

Nogués, Rafael, El majestuoso recebimiento y famosas fiestas que en la insigne ciudad de Barcelona se han hecho a la majestad de la serenisima Reina de Hungría doña Maria de Austria, que Dios guarde. Copia primera, Barcelona, Esteban Liberós, 1630.

-, Noches lucidas, pomposas y célebres fiestas que de noche se han hecho en la insigne Barcelona a la majestad de la serenisima Reina de Hungria, que Dios guarde. En diferentes versos, Barcelona, Esteban Liberós, 1630.

Pastor Silvano [apócrifo], Relación verdadera de la real embarcación de la serenísima señora doña María de Austria, Reina de Hungria, que fue miércoles a los doce de junio, a las siete horas de la tarde deste presente año de mil seiscientos y treinta. En la muy ilustre e insigne y siempre fidelisima y leal ciudad de Bar- 
celona. La cual contó el Pastor Silvano a su tan querida como hermosa Pastora Celia de los valles de Hebrón, con muchas otras cosas que pasaron, Barcelona, Esteban Liberós, 1630.

Peirón y Queralt, Martín, Verdadera relación de las fiestas que la imperial ciudad de Zaragoza ha hecho a su Rey y señor Filipo III en Aragón y IIII en Castilla. Dedicada a los muy ilustres señores don Lope de Francia, señor de Bureta y jurado en cap, don Diego Martel, don Jusepe Cerdán, don Diego Pérez y don Martín Tomás de la Nuza, supremos Attantes y jurados de dicha Ciudad, Zaragoza, Juan de Lanaja y Quartanet, 1630.

Prada y Rivera, Nicolás de, Historia de la Jornada a Alemania de la Reina de Hungría, después Emperatriz Infante de España, a quien acompañó hasta $\mathrm{Za}$ ragoza el Rey su hermano, Zaragoza, 1630.

Profeti, Maria Grazia, «Lope y las relaciones de sucesos», Revista de literatura, 74, 147 (2012), Madrid, CSIC.

—, "Poder y estrategias editoriales de Lope de Vega», en Répresentation, écriture et puvouir en Espagne à l'époque de Philippe III (1598-1621). Colloque international, Florencia, 14-15 de septiembre de 1998.

—, «Scrittori di corte e relaciones», en Encuentro de civilizaciones (1500-1750): Informar, narrar, celebrar. Actas del III Coloquio internacional sobre relaciones de sucesos (Cagliari, 5-8 de septiembre de 2001), ed. Antoni Paba y Gabriel Andrés, 2002, 223-234.

Quirós, Bernardo de, Relación verdadera de las grandiosas fiestas que se hicieron en Madrid al bautismo del Príncipe nuestro señor, Madrid, Bernardino de Guzmán, 1629.

RAMos, Rafael, «Antecedentes aureoseculares de la prensa rosa: la comedia como relación de sucesos», II Seminario sobre literatura y periodismo: "Mujer, literatura y periodismo», Facultad de Ciencias de la Comunicación, Universidad Rey Juan Carlos, 17 de noviembre de 2011.

Regocijos y fiestas que se hacen en la ciudad de Barcelona por la serenisima majestad de la Reina de Hungría, en particular en las visitas que hace a las casas de religión. Copia segunda, Los, Barcelona, Esteban Liberós, 1630.

Relación de las visitas que la majestad de la Reina de Hungria va continuando en las casas de religión. Con el espléndido convite que hizo a los pobres en dos días, que fueron el de la Virgen y el Jueves Santo, lavándoles los pies. Y regocijos y estafermo que el Embajador de Hungría, en compañia de otros caballeros forasteros, y caballeros desta ciudad, le hicieron en la plaza de San Francisco lunes a 8 de abril 1630, y sarao que en la noche hubo en el Salón de la Puente. Tercera Copia, Barcelona, Esteban Liberós, 1630.

Relación del torneo verificado en la ciudad de Zaragoza en ocasión de la llegada de la Reina de Hungría y Bohemia en el año de 1658 [sic], Zaragoza, Juan de Lanaja y Quartanet, 1630.

Relación verdadera de la entrada, recebimiento y grandiosas fiestas que la ilustre ciudad de Zaragoza hizo a sus majestades desde ocho de enero hasta catorce del dicho 
mes. Dase cuenta del torneo y saraos que se hicieron, y grandes que se hallaron en ellas, nombrándolos por sus nombres. Asi mismo se declara las costosas libreas que sacaron y premios que se dieron a las damas de la señora Reina de Hungría, Madrid, Bernardino de Guzmán, 1630.

Robles, Pedro de, Relación verdadera, acompañamiento, recámara y riquezas que lleva la majestad de la serenisima Reina de Hungría, titulos, grandes, criados, demás gente que vienen en su servicio, oficios y mercedes que se les ha hecho antes de partir, riquezas y joyas de valor que el Rey nuestro señor le ha dado a ella, como también para el Emperador y Emperatriz sus cuñados, Barcelona, Estevan Liberòs, 1630.

Rojo, Ignacio de, Relación verdadera de todo lo sucedido en el viaje de la señora Reina de Hungría, recibimientos, fiestas y desposorio. Enviada por un Padre de la Compañia de Jesús a una señora de la Corte, Barcelona, Esteban Liberós, 1631.

Rubio Árquez, Marcial, «Las relaciones en pliegos sueltos poéticos del siglo XVII», en Las relaciones de sucesos en España (1500-1750). Actas del primer Coloquio Internacional (Alcalá de Henares, 8, 9 y 10 de junio de 1995), ed. María Cruz García de Enterría, Henry Ettinghausen y Víctor Infantes, Sorbonne-Universidad de Alcalá, Alcalá de Henares, 1996, 315-330.

Santiago, Gabriel de, Relación verdadera de las fiestas reales, toros y juego de cañas que se celebraron en la corte a doce de noviembre por el nacimiento del Principe nuestro señor, con la declaración de los trajes, galas y libreas de todas las cuadrillas, Madrid, Bernardino de Guzmán, 1629.

Segunda y más verdadera relación del bautismo del Principe de España nuestro señor, Baltasar Carlos Domingo, con todos los nombres de los caballeros y títulos que iban en el acompañamiento. Con una suma de la entrada del señor Principe de Guastala, embajador de Alemania, Madrid, Bernardino de Guzmán, 1629.

Segundas tres relaciones diferentes de las que han salido de la Entrada del Duque de Guastala, embajador del Rey de Hungría. Nombrando los nombres de los caballeros que le salieron a recebir y joyas que presentó a la Reina de Hungría. Con las estaciones que anduvo la Reina nuestra señora por el feliz parto que tuvo. Fiestas y máscaras que se han hecho al nacimiento y bautismo del Principe nuestro señor, nombrando por sus nombres las damas y grandes de España que le acompañaron, con las ceremonias de la Iglesia, s.l., s.a.

Seugón, Rafael: véase Nogués, Rafael, El magestuoso recebimiento...

Shergold, Norman D., y John E. Varey, «Some Palace Performances of Seventeenth-Century Plays», Bulletin of Hispanic Studies, XL (1963), 212-244.

TéLlez, Gabriel, Breve suma y relación de las grandiosas fiestas que en la Corte se hicieron a la entrada del señor Principe de Guástala, embajador de su majestad el señor Rey de Hungría, con una loa al nacimiento del Príncipe de España, Segovia, Gerónimo Murillo, 1629.

Torneo de a caballo hecho en Zaragoza por la venida de la serenisima Señora Reyna de Hungría, en presencia del Rey nuestro señor, y de los serenisimos infantes sus 
hermanos. Relación escrita de orden de la señora Reina por un caballero de la Cámara del Rey nuestro señor. Publicado por don Miguel Batista de Lanuza, Zaragoza, Diego Latorre, 1630.

Vega, Lope de, Arte nuevo de hacer comedias en este tiempo, ed. Felipe B. Pedraza y Pedro Conde Parrado, Universidad de Castilla-La Mancha, 2016.

—, No son todos ruiseñores, ed. Miguel Ángel Auladell, Base de Datos del Teatro Español del Siglo de Oro (TESO).

Villamayor y Zayas, Francisco de, En la jornada de la serenisima señora Reina de Bohemia y Hungría, desde la Ciudad de Barcelona a Génova. Canción real, Barcelona, Sebastián Matevad, 1630. 
